3. Kaufman M, Jonat W, Kleeberg U, et al. for the German Zoladex Trial Group. Goserelin, a depot gonadotrophin-releasing hormone agonist in the treatment of premenopausal patients with metastatic breast cancer. F Clin Oncol 1989, 7, 1113-1119.

4. Grattarola R. Ovariectomy allone or in combination with dexamethasone in patients with advanced breast cancer and high levels of testosterone excretion. $\mathcal{F}$ Nall Cancer Inst 1976, 56, 11-19.

5. Secreto G, Oriana S, Recchione C. Ovariectomy alone or in combination with dexamethasone in patients with advanced breast cancer and high levels of testosterone or androstanediol excretion. Rev Endocrine-Related Cancer Su:ppl 1984, 14, 55-58.

6. Secreto G, Zumoff B. Paradoxical effects associated with supranormal urinary testosterone excretion in premenopausal women with breast cancer: increased risk of postmastectomy recurrence and higher remission rate after ovariectomy. Cancer Res 1983, 43, 3408-3412.

7. WHO Handbook for Reporting Results of Cancer Treatment. WHO Offset Publication No. 48. Geneve, 1979.

8. Ott L, Mendenhall W. Understanding Statistics, 5th Edn. PWSKENT Publishing Company, Boston, 1990.

9. Lee ET. Statistical Methods for Survival Data Analysis. Lifetime Learning Publications. Belmont, California, 1980.

10. Cox DR, Hinkley DV. Theoretical Statistics. Chapman and Hall, London, 1974.

11. SAS Institute Inc. SAS/STAT Guide for Personal Computers. Version 6 Edition. SAS Institute Inc. Cary, NC, 1987.

\title{
Peripheral Blood Progenitor Cell Transplantation Mobilised by r-metHuG-CSF (Filgrastim); a Less Costly Alternative to Autologous Bone Marrow Transplantation
}

\author{
C.A. Uyl-de Groot, D.J. Richel and F.F.H. Rutten
}

In a retrospective study, we calculated the treatment costs of 63 patients who received either autologous bone marrow transplantation (ABMT) with recombinant human granulocyte colony-stimulating factor (r-metHuG-CSF) (filgrastim) $(n=13)$ or without $r-m e t H u G-C S F ~(n=22)$ or alternatively, peripheral blood progenitor cell (PBPC) transplantation mobilised by $r-$ metHuG-CSF $(n=28)$. The recovery of granulocytes, platelets and reticulocytes after PBPC was markedly accelerated as compared with ABMT with or without r-metHuG-CSF. The accelerated haematopoietic recovery was associated with a reduction in platelets and red blood cell transfusion requirements, with a reduction in episodes of fever and with earlier discharge from the hospital. This resulted in the average cost per treatment of the PBPC group being almost $30 \%$ lower than the treatment costs in the AFMT groups.

Key words: costs, cancer, peripheral blood progenitor cells, autologous bone marrow transplantation, granulocyte colony-stimulating factor:, filgrastim

Eur F Cancer, Vol. 30A, No. 11, pp. 1631-1635, 1994

\section{INTRODUCTION}

BONE MARROW transplantation, as an adjunct to very intensive chemo- and radiotherapy, has significantly improved remission rates and survival in the treatment of acute leukaemias and malignant lymphomas. However, the procedure-associated risk of $5-15 \%$ fatal complications: and the adverse effect on patients'

Correspondence to C.A. Uyl-de Groot.

C.A. Uyl-de Groot and F.F.H. Rutten are at the Institute for Medical Technology Assessment/Department of Health Care Policy and Management, Erasmus University Rotterdam, P.O. Box 1738, 3000 DR Rotterdam; and D.J. Richel is at the Medisch Spectrum Twente, Dept. of Internal Medicine, P.O. Box 50.000, $7500 \mathrm{KA}$ Enschede, The Netherlands.

Revised 22 June 1994; accepted 26 July 1994. morbidity can be serious due to a pancytopenic period of 3-4 weeks [1]. Moreover, the costs of autologous as well as allogeneic bone marrow transplantation are high, and the additional burden that these treatments place on hospital budgets raises concern $[2,3]$. It is, therefore, relevant to not only assess the additional benefits to patients of new treatment options, but also to monitor their cost implications.

Haematopoietic growth factors make it possible to accelerate the haematopoietic recovery after an autologous bone marrow transplantation (ABMT) and thereby reduce the therapy-related toxicity. As a result, a reduction in the initial hospitalisation and in the number of days on intravenous antibiotics was demonstrated [4]. However, although the use of haematopoietic growth factors caused a shortening of the neutropenic period, 
the patients still had a median duration of severe neutropenia for 2 weeks, and had more than 3 weeks of thrombocytopenia [4]. Therefore, additional strategies to further shorten this period are required.

In recent years, autologous transplantation of peripheral blood progenitor cells (PBPC) has attracted considerable interest because of the potential advantages in comparison with bone marrow, with respect to haematopoietic recovery [5-8]. PBPC might be used in conjunction with haematopoietic growth factors to support haematopoietic recovery after high-dose chemotherapy.

This study considers the costs of PBPC transplantation mobilised by $\mathrm{r}$-metHuG-CSF (filgrastim) in comparison with ABMT without $\mathrm{r}-\mathrm{metHuG}-\mathrm{CSF}$ and AMBT with $\mathrm{r}$-metHuG-CSF. The results are based on a retrospective study of detailed records of 63 patients. The perspective of the study was the hospital's point of view, that is, all hospital costs associated with PBPC and $A B M T$ were considered.

\section{PATIENTS AND METHODS}

A total of 22 patients received ABMT without r-metHuG-CSF (six solid tumours and 16 malignant lymphomas), 13 patients recieved ABMT with $\mathbf{r}-$ metHuG-CSF (12 solid tumours and one malignant lymphoma) and 28 patients received $\mathrm{PBPC}$ with $\mathrm{r}-\mathrm{metHuG}-\mathrm{CSF}$ ( 19 solid tumours and nine malignant lymphomas) $[9,10]$. The latter group included 6 patients, who received a second PBPC reinfusion within 4 weeks. For the patients who received two reinfusions, the average costs of the two PBPC reinfusions were taken into account, as the aim of the cost analysis was to compare the costs of PBPC with the costs of ABMT. These patients received only one PBPC mobilisation and harvest; the costs of pretransplantation were not averaged.

Patients' characteristics are summarised in Table 1. The solid tumours mainly consisted of patients with breast cancer and germ cell tumours. The high-dose chemotherapy regimen of this group consisted of CTC (cyclophosphamide, thiotepa and carboplatin). The regimen for patients with malignant lymphomas consisted of carmustine, cyclophosphamide, etoposide, and cytarabine (BEAC) or cyclophosphamide, carmustine and etoposide (CBV) or carmustine, etoposide, cytarabine and melphalan (BEAM). The proportion of solid tumours and malignant lymphomas was not equal across the three treatment groups. As all treatments consisted of similar high-dose chemotherapy, regardless of ABMT or PBPC, the costs of these regimen were considered as identical and disregarded in our analysis.

The PBPC mobilisation was performed on an outpatient setting. The lymphoma and germ cell tumour patients received one course of chemotherapy, namely cyclophosphamide $(1 \mathrm{~g} /$ $\left.\mathrm{m}^{2}\right)$ on day 1 and etoposide $\left(100 \mathrm{mg} / \mathrm{m}^{2}\right)$ on days $1-3$ intravenously. The breast cancer patients received one course of FEC $\left(500 \mathrm{mg} / \mathrm{m}^{2} 5\right.$-fluorouracil, $120 \mathrm{mg} / \mathrm{m}^{2}$ epidoxorubicin and $500 \mathrm{mg} / \mathrm{m}^{2}$ cyclophosphamide). The chemotherapy was immediately followed by the administration of $r-$ metHuG-CSF at a dosage of $300 \mu \mathrm{g}$ subcutaneously, daily for 10 days.

The leucaphereses were performed with a leucapherese machine (the CS300 of Cobe) on 3 consecutive days. Both the leucaphereses and the bone marrow were cryopreserved. Additionally, a Hickman catheter was inserted. Three days after the administration of the high-dose chemotherapy, the stem cells were reinfused. The patients received $300 \mu \mathrm{g}$ r-metHuG-CSF daily until the granulocytes' recovery was stable.

The costs were considered separately for the pretransplantation and the transplantation period. The pretransplantation period included bone marrow (BM) or peripheral stem cell (PSC) harvest, cryopreservation and cultures, diagnostics, laboratories, hospitalisation, day-care department, medication, blood transfusions and the insertion of a Hickman catheter. The costs in the transplantation period related to days in hospital, laboratory services, diagnostics (mainly X-rays and ECGs), medication (antibiotics, anti-emetics, etc.) and blood transfusions. These costs have been registered through cost registry forms. Cost price studies have been carried out for all costs. The years of study were 1990-1992.

Statistical methods included Kruskal-Wallis tests for comparisons of costs and for comparisons of time-to-event outcomes for the days in hospital [11].

\section{Unit prices}

For each of the activities mentioned above, unit prices were determined reflecting the real use of resources. The year of study was 1992 ( 1 US $\$ \approx 1.8$ Dutch guilders). The unit prices are summarised in Table 2.

The cost of hospital days and treatment in a day-care department were divided into direct and indirect costs. The direct costs concerned manpower (doctors, nurses, etc.) and materials (medical devices, supportive patient care, etc.). The indirect costs were related to overheads. The cost of hospitalisation

Table 1. Patients' characteristics

\begin{tabular}{lccc}
\hline & $\begin{array}{c}\text { Control group } \\
\text { ABMT }\end{array}$ & $\begin{array}{c}\text { ABMT }+ \\
\text { r-metHuG-CSF } \\
\text { group }\end{array}$ & $\begin{array}{c}\text { PBPC }+ \\
\text { r-metHuG-CSF } \\
\text { group }\end{array}$ \\
\hline $\begin{array}{l}\text { Number of patients } \\
\text { Median age, years (range) }\end{array}$ & 22 & 13 & $28\left(34^{*}\right)$ \\
Male/Female & $30(21-54)$ & $32(18-44)$ & $41(18-60)$ \\
Diagnosis & $11 / 11$ & $7 / 6$ & $12 / 16$ \\
$\quad$ Breast cancer & 1 & 4 & 11 \\
Non-Hodgkin's lymphoma & 10 & 4 & 3 \\
Morbus Hodgkin's & 6 & 1 & 6 \\
Germ cell tumours & 5 & 4 & $6\left(11^{*}\right)$ \\
Neuroblastoma & 0 & 0 & $1\left(2^{*}\right)$ \\
Medulloblastoma & 0 & 0 & 1 \\
\hline
\end{tabular}

*6 patients received PBPC reinfusions: 5 patients with germ cell tumours and 1 patient with neuroblastoma. 
amounted to approximately US\$354 per day for normal haematological care; the direct costs were US\$238 and the indirect costs were US\$116. Staying in a protected environment cost approximately US\$552, divided into direct costs of US\$398 and indirect costs of US\$154. None of the patients was treated on an intensive care ward. A day of treatment in a day-care department cost approximately US $\$ 134$ (approximately $50 \%$ direct costs and $50 \%$ indirect costs).

The output of laboratories in The Netherlands is measured in terms of a point system, and by each point (unit of output), a cost per unit or price may be associated, which differs across types of laboratories. The prices per point varied from US\$0.62 (biochemistry and haematclogy laboratories) to US\$2.81 (virology tests). The price of a routine test (including $\mathrm{Hb}, \mathrm{Ht}$, leucocytes and thrombocytes) amounted to 5.75 points and cost US\$3.58.

For all other diagnostics, the Dutch tariff system has been used as an approximation of unit costs (an X-ray chest about US\$31 and an ECG US\$22). The cost of the insertion of a Hickman catheter was US $\$ 504$ (including the costs of the catheter). The drug prices used were wholesale prices. The costs of a $300-\mu \mathrm{g}$ vial of $\mathrm{r}-\mathrm{metHuG}-\mathrm{CSF}$ (intravenous) amounted to US $\$ 138.00$.

An additional study was performed to assess the average costs of both pretransplantation periods. The cost of BM harvest,

Table 2. Unit prices

\begin{tabular}{|c|c|}
\hline Items & $\begin{array}{l}\text { Unit cost } \\
\text { (US\$) }\end{array}$ \\
\hline \multicolumn{2}{|l|}{ Hospital stay } \\
\hline Normal haematological care & 354.00 \\
\hline Protected environment & 552.00 \\
\hline Day-care department & 134.00 \\
\hline \multicolumn{2}{|l|}{ Laboratories } \\
\hline Haematology ( $\mathrm{Hb}, \mathrm{Ht}$, leucocyte, thrombocyte) & 3.58 \\
\hline Biochemistry (sodium, potassium, creatine, glucose) & 10.58 \\
\hline $\begin{array}{l}\text { Urine } 1 \text { ( } \mathrm{pH}, \text { glucose, albumen, urobilin, bilirubin, } \\
\text { sediment) }\end{array}$ & 12.47 \\
\hline Urine 2 (creatine, sodium, albumen, total protein) & 8.71 \\
\hline Cultures (blood/urine/sputum) & 20.50 \\
\hline Virology tests & 72.94 \\
\hline Cytology (bone marrow/bronchus) & 42.59 \\
\hline \multicolumn{2}{|l|}{ Diagnostics } \\
\hline $\mathrm{X}$-ray chest & 30.94 \\
\hline $\mathrm{X}$-ray sinus & 36.92 \\
\hline Electrocardiogram (ECG) & 22.00 \\
\hline Insertion Hickman catheter & 504.00 \\
\hline Total parenteral nutrition & 83.33 \\
\hline Platelet transfusions & 74.44 \\
\hline Red cell transfusions & 98.89 \\
\hline \multicolumn{2}{|l|}{ Drugs } \\
\hline \multirow{2}{*}{ Filgrastim (r-metHuG-CSF) ( $300 \mu \mathrm{g}$ i.v.) } & 138.00 \\
\hline & Antibiotics and other medication \\
\hline e.g. Ceftazidine $2000 \mathrm{mg}$ i.v. & 161.50 \\
\hline Ciproxin $400 \mathrm{mg}$ i.v. & 77.22 \\
\hline Ciproxin $500 \mathrm{mg}$ oral & 6.84 \\
\hline Tienam $1500 \mathrm{mg}$ i.v. & 70.83 \\
\hline Teicoplanin $400 \mathrm{mg}$ i.v. & 139.00 \\
\hline Vancomycin $1000 \mathrm{mg}$ i.v. & 66.14 \\
\hline Zofran $8 \mathrm{mg}$ i.v. & 34.95 \\
\hline Zovirax $800 \mathrm{mg}$ oral & 5.97 \\
\hline
\end{tabular}

$\mathrm{Hb}$, haemaglobin; $\mathrm{Ht}$, haematocrit; i.v., intravenous.

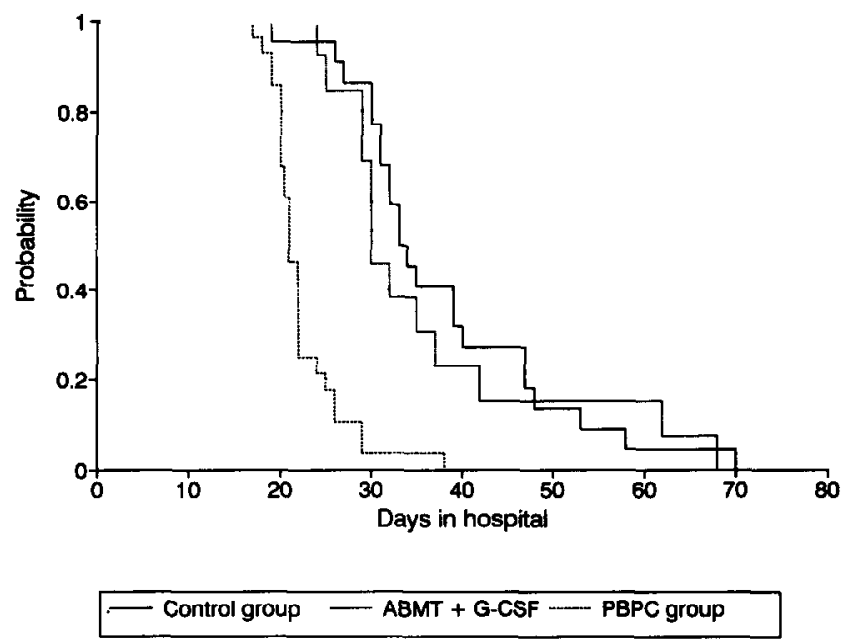

Figure 1. Mean length of hospitalisation.

cryopreservation and cultures was estimated at US\$2043. In the PBPC group, the cost amounted to US\$2740. The BM harvest was carried out on an inpatient basis, while the PCS harvest took place on an outpatient basis. The total costs of the pretransplantation period amounted to US\$5006 for both ABMT groups, and to approximately US\$5915 in the PBPC group.

\section{Clinical results}

\section{RESULTS}

Table 3 shows that haematological recovery was significantly accelerated with PBPC transplantation as compared with ABMT. The time to recovery of granulocytes to $>0.5 \times 10^{9} / 1$ was 15.0 days for the control group, 12.5 for the patients who received ABMT with $\mathrm{r}-$ metHuG-CSF and 8.0 for the PBPC group. For reticulocytes recovery to $>10 \%$, it was 23.0 days in the control group, 25.5 in the group receiving ABMT with r-metHuG-CSF and 13.5 in the PBPC group. The median number of days for platelets recovery to $>20 \times 10^{9} / 1$ in the PBPC group was approximately half that of the control group and the ABMT with r-metHuG-CSF group (10.9 versus 20.2 and 23.8 days, respectively). The median number of days for temperature recovery to $>38^{\circ} \mathrm{C}$ was also lower in the PBPC group: 2.5 versus 4.6 and 5.5 days in the $A B M T$ with and without r-metHuG-CSF, respectively.

\section{Results cost analysis}

Patients treated only with ABMT or with ABMT and r-metHuG-CSF had a mean hospital stay of 37.9 days (range 19-70) and 36.2 days (range 24-68), respectively, while patients in the PBPC group had a mean stay in hospital of 22.4 days (range 17-38) (Figure 1).

The most important cost items are summarised in Table 4. The patients in the control group stayed for 21 days in a protected environment, the ABMT with r-metHuG-CSF group 14 days and the PBPC group only 7 days.

The accelerated haematopoietic recovery in the PBPC group was associated with a reduction in platelets and red blood cell transfusion requirements. $\mathrm{r}-\mathrm{metHuG}-\mathrm{CSF}$ was given for 19.4 days (range 10-30) in the ABMT with r-metHuG-CSF group, and for 13.6 days (range 8-45) in the PBPC group.

The costs of the three treatment groups are summarised in Table 5. The differences across the groups in the cost of the pretransplantation period were in favour of the ABMT groups; 
Table 3. Clinical results

\begin{tabular}{|c|c|c|c|}
\hline . & $\begin{array}{l}\text { Control group } \\
\text { ABMT } \\
(n=22)\end{array}$ & $\begin{array}{c}\text { ABMT + } \\
\text { r-metHuG-CSF } \\
\text { group } \\
(n=13) \\
\text { (median, range) }\end{array}$ & $\begin{array}{c}\text { PBPC }+ \\
\text { r-metHuG-CSF } \\
\text { group } \\
(n=34) \\
\text { (median, range) }\end{array}$ \\
\hline Days to granulocytes recovery to $>0.5 \times 10^{9}$ & $15.0(11-17)$ & $12.5(9-18)$ & $8.0(6-11)$ \\
\hline Days to reticulocytes recovery to $>10 \%$ & $23.0(17-28)$ & $25.5(15-38)$ & $13.5(10-22)$ \\
\hline Days to thrombocytes recovery to $>20 \times 10^{9}$ & $20.2(15-40)$ & $23.8(12-38)$ & $10.9(7-25)$ \\
\hline Days to temperature recovery to $>38^{\circ} \mathrm{C}$ & $5.5(5-12)$ & $4.6(0-12)$ & $2.5(0-12)$ \\
\hline
\end{tabular}

US $\$ 5006$ for both ABMT groups versus US $\$ 5915$ for the PBPC group. However, the differences in the transplantation period were more pronounced and definitely in favour of the PBPC group. The hospitalisation costs amounted to approximately US\$17578 for the ABMT group, US\$15603 for the ABMT group with r-metHuG-CSF, and US\$9318 for the PBPC group.

Considering only costs, ABMT with r-metHuG-CSF does not seem to be a better treatment option than ABMT alone. Although the costs of hospitalisation were lower due to a shorter stay in hospital and in the protected environment, the costs of laboratory services, diagnostics, medication/nutrition and transfusions were higher.

As compared with the other treatment groups, expenditure of the PBPC group was lower for all activities. The costs of hospitalisation decreased by more than $40 \%$. The costs of medication/nutrition and transfusions were also significantly lower when compared to both ABMT groups, as were the costs of laboratory services and diagnostics.

The costs of $\mathrm{r}-\mathrm{metHuG}-\mathrm{CSF}$ were zero in the control group, US $\$ 2703$ in the ABMT with r-metHuG-CSF group, and US $\$ 1843$ in the PBPC group. The costs of antibiotics and other medication decreased from US\$3562 and US\$3593, respectively, in the ABMT groups with and without r-metHuG-CSF, US $\$ 1590$ in the PBPC group. Combining the costs of r-metHuG-CSF with medication and nutrition, the costs of medication were somewhat lower in the PBPC group (US\$3433) as compared to the control group, but this difference was not statistically significant. The medication/nutrition costs in the ABMT with $\mathrm{r}$-metHuG-CSF were remarkably higher (US\$6296) as compared with the other two groups.

The costs of transfusions decreased by more than $45 \%$, from US\$1584 and US\$2209, respectively, in the ABMT groups to US $\$ 850$ in the PBPC group.
The total costs in the transplantation period decreased by more than $35 \%$ in the PBPC group as compared with the other two groups.

Although the costs of the pretransplantation period were higher in the PBPC group than in the ABMT groups, the total treatments costs decreased significantly; from US\$30592 in the control group and US\$32443 in the ABMT with r-metHuG-CSF group to US\$21 809 in the PBPC group.

A sensitivity analysis was performed to assess the effect of changes in the costs of hospital stay, transfusions and $r-m e t H u G-C S F$. The dominance of PBPC was robust, even if the savings in hospital days were not taken into account.

\section{DISCUSSION}

The aim of our study was to assess the costs of PBPC in comparison with ABMT. Previous studies have already demonstrated the feasibility of PBPC [5-10]. Our results confirm that PBPC is an effective alternative to ABMT. ABMT is a costly procedure, as specialised care units and extensive supportive care are required. A reduction in costs through the administration of haematopoietic growth factors (HGF) could not be demonstrated in our study. Our results show a reduction of hospital days, but the costs of medication, due to the additional costs of the $\mathrm{r}-\mathrm{metHuG}-\mathrm{CSF}$, and transfusions were still higher in the ABMT with $\mathrm{r}$-metHuG-CSF group as compared with ABMT alone. However, for almost all activities, PBPC was cheaper than ABMT with or without $r-m e t H u G-C S F$.

Often new treatment options show additional benefits to patients, but also add to the health care bill. To say that this will not be true for PBPC transplantation would be a premature statement as one may expect this new option, which constitutes a lighter burden both to the patient and to the financial manager in the hospital, to diffuse more rapidly in cancer treatment than

Table 4. Most important cost items

\begin{tabular}{lccc}
\hline & $\begin{array}{c}\text { Control group } \\
\text { ABMT }\end{array}$ & $\begin{array}{c}\text { ABMT }+ \\
\text { r-metHuG-CSF } \\
\text { group } \\
(n=22)\end{array}$ & $\begin{array}{c}\text { PBPC }+ \\
\text { r-metHuG-CSF } \\
\text { group } \\
(n=28)\end{array}$ \\
\hline Number of hospital stay in days & $37.9(19-70)$ & $36.2(24-68)$ & $22.4(17-38)$ \\
(mumber of platelet transfusions & $47.1(18-179)$ & $70.8(10-161)$ & $26.7(9-100)$ \\
Number of red cell transfusions & $10.1(3-21)$ & $13.5(4-35)$ & $6.2(1-29)$ \\
Days of r-metHuG-CSF treatment & - & $19.4(10-30)$ & $13.6(8-45)$ \\
\hline
\end{tabular}


Table 5. The average costs of $A B M T$ with and without r-metHuG-CSF in comparison with $P B P C$ transplantation (in US\$)

\begin{tabular}{|c|c|c|c|}
\hline Period & $\begin{array}{l}\text { Control group } \\
\text { ABMT } \\
(n=22)\end{array}$ & $\begin{array}{c}\text { ABMT + } \\
\text { r-metHuG-CSF } \\
\text { group } \\
(n=13)\end{array}$ & $\begin{array}{c}\text { PBPC }+ \\
\text { r-metHuG-CSF } \\
\text { group } \\
(n=28)\end{array}$ \\
\hline \multicolumn{4}{|l|}{ Pretransplanation } \\
\hline \multicolumn{4}{|c|}{ BM or PSC harvest, cryopreservation } \\
\hline and cultures & 2043 & 2043 & 2740 \\
\hline Diagnostics, laboratories & 885 & 885 & 875 \\
\hline Hospitalisation/outpatient visits & 1367 & 1367 & 402 \\
\hline Medication/transfusions & 191 & 191 & 1378 \\
\hline Hickman catheter & 520 & 520 & 520 \\
\hline Total pretuansplantation & 5006 & 5006 & 5915 \\
\hline \multicolumn{4}{|l|}{ Transplantation } \\
\hline Hospitalisation & 17578 & 15603 & $9318+$ \\
\hline Laboratory & 2626 & 3006 & $2123^{*}$ \\
\hline Diagnostics & 236 & 323 & $170^{*}$ \\
\hline Medication/nutrition & 3562 & 3593 & $1590+$ \\
\hline R-metHulG-CSF (filgrastim) & $0+$ & 2703 & 1843 \\
\hline Transfusions & 1584 & 2209 & $850^{*}$ \\
\hline Total tranisplantation & 25586 & 27437 & $15894 \dagger$ \\
\hline Total treatment costs & 30592 & 32443 & $21809 \dagger$ \\
\hline
\end{tabular}

${ }^{*}$ Kruskal-Wallis test: $P<0.05$. $†$ Kruskal-Wallis test: $P<0.01 .1$ US $\$ \approx 1.8$ Dutch guilders.

ABMT. Our results suggest, however, that for patients with malignant lymphomas or solid tumours, who receive high-dose chemotherapy, PBPC transplantation is more cost-effective than $A B M T$. Further research will be needed to confirm this result. Moreover, as ABMT is associated with high mortality and morbidity rates, it may be worth also taking the effectiveness, including patients' quality of life, of PBPC into account. A "piggy-back" economic analysis (an economic evaluation performed alongside a clinical trial) may be combined with future prospective trials to confirm the dominance of PBPC over ABMT in the patient groups considered here.

1. Brandt SJ, Peters WP, Atwater SK, et al. Effect of recombinan human granulocyte-macrophage colony-stimulating factor on haematopoietic reconstruction after high-dose chemotherapy and autologous bone marrow transplantation. $N$ Englf Med 1988, 318, 593-598.

2. Dufoir T, Saux MC, Terraza B, Marit G, Guessard S, Foulon G, Reiffers J. Comparative cost of allogeneic or autologous bone marrow transplantation and chemotherapy in patients with acure myeloid leukaemia in first remission. Bone Marrow Transpl 1992, $10,323-329$.

3. Welch HG, Larson EB. Cost effectiveness of bone marrow transplantation in acute non lymphocytic leukemia. N Engl F Med 1989 , 321, 807-812.

4. Nemunaitis F, Rabinowe SN, Singer JW, et al. Recombinan granulocyte-macrophage colony stimulating factor after autologous bone marrow transplantation for lymphoid cancer. $N$ Engl $\Im$ Med 1991, 324, 1773-1778.

5. Brugger W, Bross K, Frisch J, et al. Mobilization of peripheral blood progenitor cells by sequential administration of interleukin-3 and granulocytes-macrophage colony-stimulating factor following polychemotherapy with etoposide, ifosfamide and cisplatin. Blood 1992, 5, 1193-1200.

6. Siena S, Bregni M, Brando B, Ravagnani F, Bonadonna G, Gianni

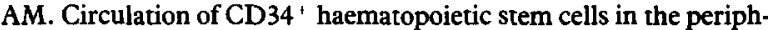
eral blood of high-dose cyclophosphamide-treated patients: enhancement by intravenous recombinant human granulocyte-macrophage colony-stimulating factor. Blood 1989, 74, 1905-1914.

7. Kessinger A, Armitage JO, Smith DM, Landmark JD, Birman PJ Weisenburger DD. High-dose therapy and autologous peripheral blood stem cell transplantation for patients with lymphoma. Blood $1989,74,1260-1265$

8. Advani R, Chao NJ, Horning SJ, et al. Granulocyte-macrophage colony-stimulating factor (GM-CSF) as an adjunct to autologous hemopoietic stem cell transplantation for lymphoma. Ann Intern Med 1992, 116, 183-189.

9. Richel DJ. Peripheral stem cell transplantation opens the way to new treatment strategies. ECC Newsletter 1992, 55-62.

10. Richel DJ, Baars JW, Wijngaarden MJGJ, Schoot CE van der, Vlasveld LT, Rodenhuis S. Favourable effect of haematopoietic stem cells isolated from blood on haematological recovery after highdose chemotherapy. Ned Tijdschr Geneeskd 1993, 137, 245-250.

11. Glantz SA. Primer of Biostatistics. Singapore, McGraw-Hill, 1989, 287-330.

Acknowledgements_Amgen and Roche are gratefully acknowledged for their support during this study. 